\title{
Determination of Possible Prognostic Indicators in Dogs with Pyometra
}

\author{
Jun-Am Lee*, Ill-Hwa Kim**, Tae-Ku Kang***, Dae-Youn Hwang**** and Hyun-Gu Kang**1 \\ *Wellcare Veterinary Hospital, Daejeon 35363, Korea \\ **Laboratory of Veterinary Theriogenology, Veterinary Teaching Hospital and College of Veterinary Medicine, \\ Chungbuk National University, Cheongju 28644, Korea \\ ***Laboratory Animal Center, Daegu-Gyeongbuk Medical Innovation Foundation, Daegu 41061, Korea \\ ****Department of Biomaterials Science, Pusan National University, Miryang 50463, Korea
}

(Received: August 11, 2020 / Accepted: August 18, 2020)

\begin{abstract}
The aims of this study were to analyze canine pyometra cases at Veterinary Medical Center of Chungbuk National University, and to identify prognostic factors of canine pyometra at the stage of diagnosis. Records of cases about intact female dogs presented to Veterinary Medical Center from 2005 to 2019 were used for analysis. A total of 147 intact female dogs with canine pyometra were analyzed from outpatients' caseload. Median outbreak age was 9.6 years (range, 8 months to 17 years). The highest prevalence of pyometra over 14 years was observed in Maltese $(22.4 \%, \mathrm{n}=33)$. Urologic disorders $(21.8 \%, \mathrm{n}=32)$ including acute renal failure and cystic calculi were the most frequently observed concurrent disorders in dogs with pyometra. In other cases of pyometra, tumor $(15.0 \%, \mathrm{n}=29)$, cardiovascular disorders $(15.0 \%, \mathrm{n}=22)$ and systemic disorders $(10.9 \%, \mathrm{n}=16)$ were accompanied with pyometra. The concentrations of BUN, creatinine and glucose were higher than reference range in cases of poor prognosis. According to the binominal logistic regression analysis, prognosis in pyometra was related to abdominal distension ( $p=0.036)$, urologic disorder $(p=0.016)$, gastrointestinal disorder $(p=0.001)$, and serum level of blood urea nitrogen (BUN) $(p=0.045)$. This study describes that prognosis of canine pyometra can be predicted at the stage of diagnosis by abdominal distension, urologic disorder, gastrointestinal disorder, and serum level of BUN.
\end{abstract}

Key words : pyometra, prognostic factor, ovariohysterectomy, dog.

\section{Introduction}

Canine pyometra is most common and potentially lifethreatening endometrial disease of middle-aged cycling females at clinical fields. The disease is characterized by accumulation of pus in the uterine lumen due to susceptible bacterial infection associated with estrous cycle. The disease has typically chronic progression with acute manifestations of various clinical symptoms at diestrus phase $(8,18)$. Development of canine pyometra is caused by complex interaction of etiological factors including change of endometrial condition, virulence and kind of infected bacteria, hormonal effects on the uterine, and defense mechanisms of individual dog $(5,12,25)$. The disease can be classified as open-cervix and closed-cervix types depending on the patency of uterine cervix. Dogs with pyometra show various clinical signs including anorexia, polydipsia and polyuria, abdominal distension, and dehydration $(15,23,31)$.

Although pyometra in dogs is generally suspected by characteristic history and clinical signs, the diagnosis with pyometra is made with radiographic and ultrasonographic findings $(2,11,17,27)$. Dogs with pyometra have also hematologic and biochemical abnormalities including leukocytosis, anemia, hypoalbuminemia, increased activity of serum alkaline phos-

${ }^{1}$ Corresponding author.

E-mail : kang6467@cbu.ac.kr phatase (ALP), and increased concentration of blood urea nitrogen $(\mathrm{BUN})$ and creatinine $(7,12,15,21)$.

The treatment of choice for pyometra consists of medical therapy and surgical removal. However, complete ovariohysterectomy (OHE) is recommended for the most effective treatment and proper supportive therapy should be accompanied with surgery based on the patient's status (1). Because $\mathrm{OHE}$ is performed under general anesthesia, if status of patient was not evaluated before surgery, postoperative prognosis may be influenced. Therefore, decision and point of time of surgery should be determined based on the preoperational evaluation of patient's general condition and survey radiographs as well as hematologic tests including the concentration of serum protein (total protein and albumin), renal function (BUN and creatinine), the activities of liver enzymes (alanine aminotransferase (ALT) and ALP), electrolyte balance (sodium, chloride and potassium), and complete blood counts (CBC). If there are hematological abnormalities and dehydration, aggressive fluid therapy with appropriate antibiotics should be performed prior to OHE for improving the surgical outcome with reduced morbidity.

Prognosis of pyometra has been reported to be vary with relatively low mortality of 3-4\%. However, pyometra-associated systemic complications such as disseminated intravascular coagulation, systemic inflammatory response syndrome (SIRS), multiple organ dysfunction syndrome (MODS), and higher blood concentrations of endotoxin are related with poor prognosis $(4,26,28)$. Several studies reported prostaglan- 
din $\mathrm{F}_{2 \alpha}$ metabolite (PGFM), tumor necrosis factor (TNF), interleukin (IL)-1, IL-6, platelet activating factors (PAF), and central venous oxygen saturation and base deficit as prognostic indicators of canine pyometra $(6,17,28,30)$. However, measuring systems for these indicators are not widely available in clinical laboratories. Therefore, prognostic factors for canine pyometra are needed to be determined which can be easily and promptly measured at the time of diagnosis. The purposes of this study was to evaluate the clinical characteristics of dogs with pyometra and to determine prognostic factors of canine pyometra.

\section{Materials and Methods}

\section{Study population}

Clinical records were obtained from database of dogs with pyometra from Veterinary Medical Center in Chungbuk National University between 2005 to 2019. A total of 147 intact female dogs with pyometra were enrolled in the present study.

\section{Diagnosis}

Initial diagnosis of pyometra was made based on history taking, physical examination, abdominal radiographic findings (Directview CR500; Eastman Kodak Co., NY, USA), and abdominal ultrasonographic findings (ProSound Alpha 5; Hitachi Aloka Medical, Tokyo, Japan). According to the history taking and physical examination, intact female dogs having vaginal discharge combined with polyuria and polydipsia, abdominal distension, and palpable enlarged uterus were suspected to have pyometra. On survey radiograph, pyometra was diagnosed from observation of tubular structure between the urinary bladder and descending colon at lateral abdominal view. Dogs with abnormal ultrasonographic findings, such as fluid-filled uterus or uterine horn were diagnosed as pyometra. The presence of concurrent disorders was also evaluated by history taking, physical examination, radiographic and ultrasonographic findings, and laboratory findings such as serum chemistry (Hitachi 7202; Hitachi HighTechnologies Co., Toyko, Japan), electrolytes analyses (Humalyte; HUMAN Gesellschaft fur Biochemica und Diagnostica $\mathrm{mbH}$, Wiesbaden, Germany), and $\mathrm{CBC}$ (BC-5300 Vet TM; Mindray Co., Shenzhen, China).

\section{Data collection}

Data were collected from the clinical records of selected 147 dogs. The following data were individually collected from case of pyometra: breed, age, body weight, clinical signs on admission (vaginal discharge, anorexia, depression, lethargy, vomiting, diarrhea, polydipsia and polyuria, abdominal distension, fever, and dehydration status), presence of concurrent disorders, results of hematological and biochemical analyses, treatment (surgery or medical treatments), duration of hospitalization, and prognosis. Concurrent disorders were categorized as cardiovascular, respiratory, urologic, gastrointestinal, endocrine, neurologic, musculoskeletal, tumor, and systemic disorders. In this study, cardiovascular disorder included chronic valvular heart disease, heart worm disease, and systemic hypertension. Respiratory disorder included pul- monary hypertension, pleural effusion, and tracheal collapse. Urologic disorders included chronic kidney disease, acute kidney injury, urolithiasis, and cystitis. Gastrointestinal disorders included pancreatitis, gastric foreign body, and parvoviral enteritis. Endocrine disorders included hyperadrenocorticism and diabetes mellitus. Neurologic disorders included intervertebral disc herniation and discospondylitis. Musculoskeletal disorders included patellar luxation and cruciate ligament injury. Tumor included mammary gland tumor, vaginal mass and tumor in other systems. Systemic disorders included SIRS, MODS, and peritonitis.

\section{Case reviews}

Clinical records and signalment of dogs with pyometra were reviewed by each case from presentation to discharge or death including euthanasia. Outcome of pyometra was determined on 14 days after the initial diagnosis with pyometra. Dogs were considered to have a poor prognosis when they died or were euthanized while hospitalized, and if they were discharged upon their owner's request due to worsening clinical condition during hospitalization within 14 days from initial diagnosis with pyometra.

\section{Statistical analysis}

Clinical data were statistically analyzed for determining prognostic factors for the outcome of pyometra. All statistical analyses were performed by using SPSS (version 12, SPSS Inc., IBM company) with significance set as $p<0.05$. Numerical variables such as age, electrolytes, serum chemistry, and $\mathrm{CBC}$ were divided into two categories (one for $<$ median value; the other for $\geq$ median value) for binominal logistic regression tests. Categorical variables such as breed, body weight, season of presentation, types of pyometra, clinical signs, concurrent disorders, and categorized numerical variables were analyzed using binominal logistic regression analysis. Variables were individually compared with prognosis by using a Chi-squire test for the purpose of gathering possible prognostic factors. Correlation between variables were evaluated using Pearson's correlation test with $p<0.15$ for eliminating interaction effects between independent variables. Putative variables were verified as prognostic factors by binominal logistic regression tests. These were repeated after each variable with the highest $p$-value was excluded until variables with $p$-value lower than 0.05 were detected. Data were expressed as mean \pm standard error (SE) or percentage (\%).

\section{Results}

\section{Prevalence of pyometra}

A total of 147 cases were initially diagnosed as pyometra in the 14-year period of study. The prevalence of pyometra according to breeds is summarized in Table 1. The highest prevalence of pyometra over 14 years was observed in Maltese $(22.4 \%, n=33)$. Maltese, Yorkshier Terrier, Miniature Schnauzer and Poodle showed higher prevalence of pyometra than the other breeds.

A mean age of dogs with pyometra were $9.6 \pm 3.4$ years (range, 8 months to 17 years). A mean age of dogs with pyo- 
Table 1. The mean age in 147 dogs with pyometra within breeds

\begin{tabular}{|c|c|c|c|}
\hline \multirow{2}{*}{ Breeds } & \multirow{2}{*}{$\begin{array}{l}\text { No. of } \\
\text { dogs }\end{array}$} & Age & \multirow{2}{*}{$95 \% \mathrm{CI}^{*}$} \\
\hline & & Mean \pm SD & \\
\hline Maltese & $33(22.4)$ & $10.2 \pm 2.8$ & $8.95-11.40$ \\
\hline Yorkshire Terrier & $19(12.9)$ & $9.1 \pm 4.0$ & $6.78-11.22$ \\
\hline Shih Tzu & $10(6.8)$ & $10.3 \pm 3.3$ & $8.30-12.32$ \\
\hline Miniature Schnauzer & $15(10.2)$ & $9.6 \pm 3.4$ & $7.27-11.82$ \\
\hline Poodle & $14(9.5)$ & $11.2 \pm 2.8$ & $9.21-12.99$ \\
\hline Pekingese & $9(6.1)$ & $7.7 \pm 1.2$ & $5.50-8.78$ \\
\hline Jindo & $6(4.1)$ & $7.8 \pm 5.7$ & $-1.38-16.88$ \\
\hline Mongrel & $18(12.2)$ & $10.7 \pm 3.5$ & $8.03-12.64$ \\
\hline Other breeds & $23(15.6)$ & $8.1 \pm 3.3$ & $6.98-10.08$ \\
\hline Total & $147(100)$ & $9.6 \pm 3.4$ & 8.94-10.19 \\
\hline
\end{tabular}

${ }^{*}$ CI, confidence interval.

metra varies among breeds; 7.7 years for Pekingese (95\% confidence interval (CI), 5.5 to 8.78 ) and 11.2 years for Poodle $(95 \%$ CI, 9.2 to 13.0$)$ (Table 1$)$.

\section{Concurrent disorders}

Urologic disorders $(21.8 \%, \mathrm{n}=32)$ including acute renal failure and cystic calculi were the most frequently observed concurrent disorders in dogs with pyometra. In other cases of pyometra, tumor $(15.0 \%, \mathrm{n}=29)$, cardiovascular disorders $(15.0 \%, \mathrm{n}=22)$ and systemic disorders $(10.9 \%, \mathrm{n}=16)$ were accompanied with pyometra (Table 2 ).
Table 2. Proportion of concurrent disorders in 147 dogs with pyometra

\begin{tabular}{lcc}
\hline \hline Concurrent disorders & Number of dogs & Proportion (\%) \\
\hline Urologic & 32 & 21.8 \\
Tumor & 29 & 19.7 \\
Cardiovascular & 22 & 15.0 \\
Systemic & 16 & 10.9 \\
Gastrointestinal & 13 & 8.8 \\
Endocrine & 10 & 6.8 \\
Respiratory & 7 & 4.8 \\
Hepatobiliary & 7 & 4.8 \\
Dirofilariasis & 7 & 4.8 \\
Musculoskeletal & 4 & 2.7 \\
Neurologic & 3 & 2.0 \\
None & 41 & 27.9 \\
\hline
\end{tabular}

\section{Blood profiles}

Characteristics of blood profile between good and poor prognosis in dogs with pyometra are shown in Table 3. Blood electrolytes were in the reference range regardless of prognosis. In serum chemistry, concentration of total protein and activity of ALT were in the reference range, and concentration of serum albumin was lower than reference range and activity of ALP was higher than reference range regardless of prognosis. However, albumin-globulin ratio was lower, and concentrations of BUN, creatinine and glucose were higher

Table 3. Characteristics of electrolytes, serum biochemistry, and complete blood counts in 147 dogs with pyometra between good and poor prognosis

\begin{tabular}{|c|c|c|c|c|}
\hline & \multirow{2}{*}{ Unit } & \multirow{2}{*}{ Reference range } & \multicolumn{2}{|c|}{ Mean \pm SE } \\
\hline & & & Good prognosis & Poor prognosis \\
\hline \multicolumn{5}{|l|}{ Electrolyte } \\
\hline Sodium & $\mathrm{mmol} / \mathrm{L}$ & $141-152$ & $144.6 \pm 0.9$ & $143.4 \pm 2.4$ \\
\hline Chloride & $\mathrm{mmol} / \mathrm{L}$ & $105-115$ & $112.2 \pm 0.9$ & $106.2 \pm 3.2$ \\
\hline Potassium & $\mathrm{mmol} / \mathrm{L}$ & $3.6-5.8$ & $4.36 \pm 0.08$ & $4.49 \pm 0.20$ \\
\hline \multicolumn{5}{|l|}{ Serum biochemistry } \\
\hline Total protein & $\mathrm{g} / \mathrm{dL}$ & $5.4-7.1$ & $6.56 \pm 0.10$ & $6.01 \pm 0.29$ \\
\hline Albumin & $\mathrm{g} / \mathrm{dL}$ & $2.6-3.3$ & $2.43 \pm 0.07^{*}$ & $2.11 \pm 0.13^{*}$ \\
\hline A-G ratio & - & $0.59-1.11$ & $0.63 \pm 0.03$ & $0.58 \pm 0.05^{*}$ \\
\hline BUN & $\mathrm{mg} / \mathrm{dL}$ & $7.0-25.0$ & $22.44 \pm 2.10$ & $64.69 \pm 11.33^{* *}$ \\
\hline Creatinine & $\mathrm{mg} / \mathrm{dL}$ & $0.5-1.5$ & $0.86 \pm 0.06$ & $2.65 \pm 0.539^{* *}$ \\
\hline ALT & $\mathrm{IU} / \mathrm{L}$ & $21-102$ & $47.1 \pm 5.3$ & $75.7 \pm 25.8$ \\
\hline ALP & IU/L & $29-97$ & $478.7 \pm 52.3^{* *}$ & $870.0 \pm 2137^{* *}$ \\
\hline Glucose & $\mathrm{mg} / \mathrm{dL}$ & $65-118$ & $112.2 \pm 5.7$ & $182.7 \pm 59.0^{* *}$ \\
\hline \multicolumn{5}{|l|}{ Complete blood counts } \\
\hline WBC & $/ \mu \mathrm{L}$ & $6,000-17,000$ & $22,190.9 \pm 2,113.1^{* *}$ & $21,657.9 \pm 4,955.0^{* *}$ \\
\hline Neutrophils & $/ \mu \mathrm{L}$ & $3,000-11,800$ & $18,153.7 \pm 1,909.0^{* *}$ & $17,908.9 \pm 4,512.4^{* *}$ \\
\hline Monocytes & $/ \mu \mathrm{L}$ & $200-2,000$ & $1,932.8 \pm 250.7$ & $1,588.1 \pm 368.3$ \\
\hline Lymphocytes & $/ \mu \mathrm{L}$ & $1,000-4,800$ & $1,578.7 \pm 127.08$ & $1,256.7 \pm 271.4$ \\
\hline PCV & $\%$ & $37-55$ & $40.5 \pm 1.0$ & $38.0 \pm 2.1$ \\
\hline Platelet & $\times 10^{3} / \mu \mathrm{L}$ & $200-500$ & $307.5 \pm 24.4$ & $243.5 \pm 39.1$ \\
\hline
\end{tabular}

SE, standard error; SD, standard deviation; A-G ratio, albumin-globulin ratio; BUN, blood urea nitrogen; ALT, alanine aminotransferase; ALP, alkaline phosphatase; WBC, white blood cell; PCV, packed cell volume.

* Lower than reference range.

${ }^{* *}$ Higher than reference range. 
Table 4. Result of binominal logistic regression test for variables retained after Chi-squire test and Pearson's correlation test with significance at $p<0.15(\mathrm{n}=135)$

\begin{tabular}{|c|c|c|c|c|c|c|c|}
\hline & \multirow{2}{*}{ Criteria } & \multicolumn{2}{|c|}{ Outcome } & \multirow{2}{*}{ Wald Chi-squire } & \multirow{2}{*}{ OR } & \multirow{2}{*}{$95 \% \mathrm{CI}$} & \multirow{2}{*}{$p$-value } \\
\hline & & Poor & Good & & & & \\
\hline \multicolumn{8}{|l|}{ Signalment } \\
\hline Weight & $\begin{array}{l}<5 \mathrm{~kg} \\
\geq 5 \mathrm{~kg}\end{array}$ & $\begin{array}{c}18(13.3 \%) \\
9(6.7 \%)\end{array}$ & $\begin{array}{l}52(38.5 \%) \\
56(41.5 \%)\end{array}$ & 0.203 & 1.511 & $0.251-9.092$ & 0.326 \\
\hline \multicolumn{8}{|l|}{ Clinical signs } \\
\hline Dehydration & $\begin{array}{l}<8 \% \\
\geq 8 \%\end{array}$ & $\begin{array}{l}10(7.4 \%) \\
16(11.9 \%)\end{array}$ & $\begin{array}{l}92(68.1 \%) \\
17(12.6 \%)\end{array}$ & 1.607 & 3.351 & $0.517-21.736$ & 0.103 \\
\hline Vaginal discharge & $\begin{array}{l}\text { No } \\
\text { Yes }\end{array}$ & $\begin{array}{c}18(13.3 \%) \\
9(6.7 \%)\end{array}$ & $\begin{array}{l}38(28.1 \%) \\
70(51.9 \%)\end{array}$ & 0.715 & 0.484 & $0.090-2.605$ & 0.194 \\
\hline Anorexia & $\begin{array}{l}\text { No } \\
\text { Yes }\end{array}$ & $\begin{array}{c}7(5.2 \%) \\
19(14.1 \%)\end{array}$ & $\begin{array}{l}40(29.6 \%) \\
69(51.1 \%)\end{array}$ & 0.098 & 0.714 & $0.087-5.861$ & 0.377 \\
\hline Depression & $\begin{array}{l}\text { No } \\
\text { Yes }\end{array}$ & $\begin{array}{l}15(11.1 \%) \\
11(8.1 \%)\end{array}$ & $\begin{array}{l}53(39.3 \%) \\
56(41.5 \%)\end{array}$ & 0.638 & 0.473 & $0.075-2.972$ & 0.212 \\
\hline Abdominal distension & $\begin{array}{l}\text { No } \\
\text { Yes }\end{array}$ & $\begin{array}{l}14(10.4 \%) \\
13(9.6 \%)\end{array}$ & $\begin{array}{l}77(57.0 \%) \\
31(23.0 \%)\end{array}$ & 1.300 & 2.980 & $0.456-19.467$ & 0.127 \\
\hline \multicolumn{8}{|l|}{ Concurrent disorders } \\
\hline Urologic & $\begin{array}{l}\text { No } \\
\text { Yes }\end{array}$ & $\begin{array}{l}14(10.4 \%) \\
13(9.6 \%)\end{array}$ & $\begin{array}{l}89(65.9 \%) \\
19(14.1 \%)\end{array}$ & 3.054 & 4.991 & $0.823-30.286$ & 0.041 \\
\hline Gastrointestinal & $\begin{array}{l}\text { No } \\
\text { Yes }\end{array}$ & $\begin{array}{l}17(12.6 \%) \\
10(7.4 \%)\end{array}$ & $\begin{array}{r}104(77.0 \%) \\
4(3.0 \%)\end{array}$ & 5.394 & 18.368 & $1.575-214.187$ & 0.010 \\
\hline Systemic & $\begin{array}{l}\text { No } \\
\text { Yes }\end{array}$ & $\begin{array}{c}18(13.3 \%) \\
8(5.9 \%)\end{array}$ & $\begin{array}{r}102(75.6 \%) \\
7(5.2 \%)\end{array}$ & 0.231 & 0.509 & $0.033-7.985$ & 0.316 \\
\hline \multicolumn{8}{|l|}{ Blood profiles } \\
\hline Albumin & $\begin{array}{l}<2.3 \mathrm{~g} / \mathrm{dL} \\
\geq 2.3 \mathrm{~g} / \mathrm{dL}\end{array}$ & $\begin{array}{l}16(11.9 \%) \\
11(8.1 \%)\end{array}$ & $\begin{array}{l}47(34.8 \%) \\
61(45.2 \%)\end{array}$ & 0.444 & 0.520 & $0.076-3.551$ & 0.253 \\
\hline Blood urea nitrogen & $\begin{array}{l}<19.05 \mathrm{mg} / \mathrm{dL} \\
\geq 19.05 \mathrm{mg} / \mathrm{dL}\end{array}$ & $\begin{array}{c}6(4.4 \%) \\
21(15.6 \%)\end{array}$ & $\begin{array}{l}62(45.9 \%) \\
46(34.1 \%)\end{array}$ & 0.656 & 2.223 & $0.322-15.375$ & 0.209 \\
\hline Creatinine & $\begin{array}{l}<0.8 \mathrm{mg} / \mathrm{dL} \\
\geq 0.8 \mathrm{mg} / \mathrm{dL}\end{array}$ & $\begin{array}{c}6(4.5 \%) \\
20(14.8 \%)\end{array}$ & $\begin{array}{l}55(40.7 \%) \\
54(40.0 \%)\end{array}$ & 0.093 & 0.728 & $0.095-5.583$ & 0.380 \\
\hline Glucose & $\begin{array}{l}<108 \mathrm{mg} / \mathrm{dL} \\
\geq 108 \mathrm{mg} / \mathrm{dL}\end{array}$ & $\begin{array}{l}13(9.6 \%) \\
11(8.1 \%)\end{array}$ & $\begin{array}{l}53(39.3 \%) \\
58(43.0 \%)\end{array}$ & 0.172 & 0.730 & $0.165-3.224$ & 0.339 \\
\hline Platelet & $\begin{array}{l}<278 \times 10^{3} / \mu \mathrm{L} \\
\geq 278 \times 10^{3} / \mu \mathrm{L}\end{array}$ & $\begin{array}{c}20(14.8 \%) \\
7(5.2 \%)\end{array}$ & $\begin{array}{l}48(35.6 \%) \\
60(44.4 \%)\end{array}$ & 1.093 & 0.336 & $0.044-2.593$ & 0.148 \\
\hline Total & & $29(19.7 \%)$ & $118(80.3 \%)$ & & & & \\
\hline
\end{tabular}

OR, odd ratio; CI, confidence interval.

Table 5. Variables predicted as prognostic factors after repetitive binominal logistic regression tests

\begin{tabular}{lcccc}
\hline \hline & Wald Chi-squire & OR & $95 \%$ CI & $p$-value \\
\hline Abdominal distension & 4.406 & 4.354 & $1.102-17.193$ & 0.036 \\
Urologic disorder & 5.816 & 5.319 & $1.368-20.690$ & 0.016 \\
Gastrointestinal disorders & 10.093 & 20.899 & $3.204-136.319$ & 0.001 \\
Blood urea nitrogen & 4.002 & 3.941 & $1.028-15.108$ & 0.045 \\
\hline
\end{tabular}

OR, odd ratio; CI, confidence interval.

than reference range in cases of poor prognosis. In $\mathrm{CBC}$, $\mathrm{PCV}$ and platelet counts were in the reference range, but WBC and neutrophils were higher than reference range in dogs with pyometra, who had good or poor prognosis.

\section{Prognostic factors}

As results of the Chi-squire test and Pearson's correlation test with significance of $p<0.150,14$ variables including weight, dehydration, vaginal discharge, anorexia, depression, abdominal distension, urologic disorder, gastrointestinal disorder, systemic disorder, albumin, BUN, creatinine, glucose and platelet counts were retained (Table 4). After repetitive binominal logistic regression tests with these variables, abdominal distension (OR 4.354, $p=0.036$ ), urologic disor- 
der (OR 5.319, $p=0.016$ ), gastrointestinal disorders (OR 20.899, $p=0.001$ ), and BUN (OR 3.941, $p=0.045$ ) were found to be significant prognostic factors in pyometra (Table 5).

\section{Discussion}

Canine pyometra is commonly diagnosed disease of reproductive system at routine clinical fields, but one of the potentially life-threatening disease $(4,26,28)$. Therefore, prompt and accurate diagnosis and prediction of prognosis are essential factors for proper treatment for dogs with pyometra. Therefore, instead of difficult and time spending methods, identifying prognostic factors according to the evaluation and analyses of various characteristics at the time of diagnosis are advocated in clinical patients with pyometra.

The prevalence of pyometra within ovary-intact female dogs was $3.5 \%$ in this study. This result was higher than previously reported prevalence $(14,33)$. Although the present study did not investigate, this could be associated with relatively low elective neutering rate compared with countries in which elective neutering is generally performed. The continuous increase of annual prevalence in pyometra cases also may be related with low rate of elective neutering compared with increased population of breeding dogs since 2000s. Owners need to be educated on the importance of elective neutering for their companion animal because many owners do not aware the risk of reproductive-associated life-threatening problems such as pyometra and mammary gland tumor, and the fact that these problems can be prevented by neutering.

In this study, Maltese, Yorkshire Terrier, Miniature Schnauzer, and Poodle showed higher prevalence of pyometra than other breeds. This was inconsistent with previous study which described that Miniature Schnauzer and Poodle had significantly lower risk for developing pyometra than other breeds (22). A genetic predisposition of pyometra has not been evaluated, but, several studies have described the high prevalence of pyometra within certain breeds including Bullmastiff, Golden Retriever, Rottweiler and Miniature Schnauzer $(14,20,24)$. Present study could not demonstrate that breed-specific risk of pyometra because statistical analysis was not performed.

The mean age of the cases (9.6 years) in this study is similar with study on colony-reared Beagles (13) but older than other studies $(8,14,24)$. Higher mean age may be associated with relatively high distribution of small and toy breed. Distribution of canine breed in Korea is not described yet, so further study is required. Variation in age at pyometra among breeds was consistent with previous study (14). However, in the present study, Pekingese was presented with pyometra at younger age ( 7.7 years) and Poodle was presented at older (11.2 years) than other breeds, which were not discussed in previous studies $(14,24)$. One study described that risk of pyometra and developing age may be associated with breeds by possible genetic predisposition (9).

In the present study, mean interval from the last known estrus to presentation was 10.3 weeks (data not shown), which was similar with previous reports (2). Based on the history taking, duration from onset of clinical signs to admission was 8.39 days, which indicated that most of clinical signs of pyo- metra were nonspecific when compared with the other disorders. In author's opinion, beside cases of vaginal discharge, most of owners may not become suspicious of pyometra only based on clinical signs. The proportion of clinical signs was not different with previous studies (15,31).

In the present study, urologic disorder including acute renal failure and cystic calculi, cardiovascular disorder including myxomatous mitral valve disease, tumor including mammary gland tumor, and systemic disorders including septic peritonitis and sepsis were common disorders accompanied with pyometra. Urologic disorder, especially, azotemia and acute renal failure may be derived from dehydration, and can be resolved by immediate fluid therapy or surgery $(19,32)$. Sepsis is defined as widespread inflammation caused by bacterial infection (3). Septic peritonitis with pyometra results from effluence of infectious fluid into abdominal cavity by uterine rupture or leakage from oviduct (29). Dogs with sepsis and septic peritonitis in case of pyometra need prompt and aggressive treatment, but these cases often show poor prognosis.

Dogs with pyometra showed various abnormalities of hematological and biochemical variables $(7,12,15,21)$. In present study, abnormal patterns of blood profiles were similar with previous studies (12,21). Degree of electrolyte imbalance may be caused by severity and duration of dehydration. Increased concentrations of BUN and creatinine were common complications of pyometra, and they may be also caused by dehydration associated with anorexia and vomiting $(17,32)$. In dogs with pyometra, mean concentration of albumin was lower than reference range, but concentration of total protein was within the reference range. This means that albumin was lost through kidney and/or was under produced by hepatic disease but acute phase protein such as C-reactive protein and gamma-globulin in response to chronic antigen stimulation were increased as acute and chronic inflammatory reaction $(4,12,21)$. The mean activity of ALP $(552.9 \pm$ $60.4 \mathrm{IU} / \mathrm{L}$ ) was increased. This indicated that toxemia originated from pyometra may inhibit synthesis of liver enzyme and damage to the hepatic membrane $(2,21)$. Leukocytosis with neutrophilia was assessed as response of leukocytes to inflammation. But, mean count of lymphocyte was in low level of reference range, indicating that suppression of lymphocyte activity may be induced by toxemia (10).

According to the previous investigations, endotoxin concentration, PGFM, TNF, IL-1, IL-6, PAF and central venous oxygen saturation and base deficit were reported as prognostic indicators $(6,16,26,28,30)$. But none of them was currently available for routine clinical use (17). Endotoxin concentrations are difficult to measure (12) and PGFM analysis is possible prognostic value in pyometra, but follow-up studies have not yet been performed (17). Uncontrolled production of TNF, ILs and PAF may indicate irreversible internal organ damage or septic shock (28). One study using central venous oxygen concentration and base deficit as prognostic indicators for sepsis showed that these parameters could be used as prognostic indicator in pyometra (6). However, these parameters are difficult to measure so that they are not easily available in routine veterinary clinics. Abdominal distension, urologic disorder, gastrointestinal disorder and serum level of 
BUN was determined as prognostic factors in the present study. Abdominal distension may be caused by enlarged uterus of closed-cervix type pyometra or ascites induced by septic peritonitis in pyometra. As previously described, progression of closed-cervix type pyometra and septic peritonitis are closely related with poor prognosis. Urologic disorders such as acute renal dysfunction can lead to electrolyte imbalance and hypoalbuminemia, which may have delayed immediate surgical treatments with prolonged hospitalization. Pancreatitis is typical disorder of gastrointestinal system in pyometra cases, which may be caused by reflux of gastrointestinal contents during vomiting under the condition of anorexia. Azotemia associated with pyometra is a marker of renal damage and/or may be the cause of vomiting (32).

In conclusion, canine pyometra should be regarded as one of the emergency condition because early diagnosis and prompt treatment are necessary to prevent a fatal outcome. This results indicate that prognostic indicators of canine pyometra including abdominal distension, urologic disorder, gastrointestinal disorder and BUN concentration can be used to expect the prognosis of the disease and support in decision on the direction of treatment in private veterinary clinics.

\section{References}

1. Biddle D, Macintire DK. Obstetrical emergencies. Clin Tech Small Anim Pract 2000; 15: 88-93.

2. Bigliardi E, Parmigiani E, Cavirani S, Luppi A, Bonati L, Corradi A. Ultrasonography and cystic hyperplasia-pyometra complex in the bitch. Reprod Domest Anim 2004; 39: 136140.

3. Bone RC, Balk RA, Cerra FB, Dellinger RP, Fein AM, Knaus WA, Schein RM, Sibbald WJ. Definitions for sepsis and organ failure and guidelines for the use of innovative therapies in sepsis. The ACCP/SCCM Consensus Conference Committee. American College of Chest Physicians/Society of Critical Care Medicine. Chest 1992; 101: 1644-1655.

4. Borresen B. Pyometra in the dog. II.-A pathophysiological investigation. II. Anamnestic, clinical and reproductive aspects. Nord Vet Med 1979; 31: 251-257.

5. Coggan JA, Melville PA, de Oliveira CM, Faustino M, Moreno AM, Benites NR. Microbiological and histopathological aspects of canine pyometra. Braz J Microbiol 2008; 39: 477-483.

6. Conti-Patara A, de Araujo Caldeira J, de Mattos-Junior E, de Carvalho Hda S, Reinoldes A, Pedron BG, Patara M, Francisco Talib MS, Faustino M, de Oliveira CM, Cortopassi SR. Changes in tissue perfusion parameters in dogs with severe sepsis/septic shock in response to goal-directed hemodynamic optimization at admission to ICU and the relation to outcome. J Vet Emerg Crit Care 2012; 22: 409-418.

7. de Schepper J, van der Stock J, Capiau E. The characteristic pattern of aspartate aminotransferase and alanine aminotransferase in the bitch with the cystic hyperplasia-pyometra complex: effect of medical or surgical treatment. Vet Res Commun 1987; 11: 65-75.

8. Dow C. The cystic hyperplasia-pyometra complex in the bitch. J Comp Pathol 1959; 69: 237.

9. Egenvall A, Hagman R, Bonnett BN, Hedhammar A, Olson P, Lagerstedt AS. Breed risk of pyometra in insured dogs in Sweden. J Vet Intern Med 2001; 15: 530-538.
10. Faldyna M, Laznicka A, Toman M. Immunosuppression in bitches with pyometra. J Small Anim Pract 2001; 42: 5-10.

11. Fayrer-Hosken RA, Mahaffey M, Miller-Liebl D, Caudle AB. Early diagnosis of canine pyometra using ultrasonography. Vet Radiol 1991; 32: 287-289.

12. Fransson B, Lagerstedt AS, Hellmen E, Jonsson P. Bacteriological findings, blood chemistry profile and plasma endotoxin levels in bitches with pyometra or other uterine diseases. Zentralbl Veterinarmed A. 1997; 44: 417-426.

13. Fukuda S. Incidence of pyometra in colony-raised beagle dogs. Exp Anim 2001; 50: 325-329.

14. Gibson A, Dean R, Yates D, Stavisky J. A retrospective study of pyometra at five RSPCA hospitals in the UK: 1728 cases from 2006 to 2011. Vet Rec 2013; 173: 396.

15. Gilbert RO, Nothling JO, Oettle EE. A retrospective study of 40 cases of canine pyometra-metritis treated with prostaglandin F-2 alpha and broad-spectrum antibacterial drugs. J Reprod Fertil (Suppl) 1989; 39: 225-229.

16. Hagman R, Kindahl H, Lagerstedt AS. Pyometra in bitches induces elevated plasma endotoxin and prostaglandin $F_{2 \alpha}$ metabolite levels. Acta Vet Scand 2006; 47: 55-67.

17. Hagman R. Diagnostic and prognostic markers for uterine diseases in dogs. Reprod Domest Anim (Suppl 2) 2014; 49: 16-20.

18. Hagman R, Lagerstedt AS, Hedhammar A, Egenvall A. A breed-matched case-control study of potential risk-factors for canine pyometra. Theriogenology 2011; 75: 1251-1257.

19. Heiene R, Moe L, Molmen G. Calculation of urinary enzyme excretion, with renal structure and function in dogs with pyometra. Res Vet Sci 2001; 70: 129-137.

20. Jitpean S, Hagman R, Strom Holst B, Hoglund OV, Pettersson A, Egenvall A. Breed variations in the incidence of pyometra and mammary tumours in Swedish dogs. Reprod Domest Anim (Suppl 6) 2012; 47: 347-350.

21. Kaymaz M, Bastan A, Erunal N, Aslan S, Findik M. The use of laboratory findings in the diagnosis of CEH-pyometra complex in the bitch. Turk J Vet Anim Sci 1999; 23: 127-133.

22. Krook L, Larsson S, Rooney JR. The interrelationship of diabetes mellitus, obesity, and pyometra in the dog. Am J Vet Res 1960; 21: 120-127.

23. Nelson RW, Feldman EC, Stabenfeldt GH. Treatment of canine pyometra and endometritis with prostaglandin F2 alpha. J Am Vet Med Assoc 1982; 181: 899-903.

24. Niskanen M, Thrusfield MV. Associations between age, parity, hormonal therapy and breed, and pyometra in Finnish dogs. Vet Rec 1998; 143: 493-498.

25. Nomura K, Nishida A. Histological variations of canine deciduoma induced in non pregnant horn at different stages of unilateral pregnancy. J Vet Med Sci 1998; 60: 623-626.

26. Okano S, Tagawa M, Takase K. Relationship of the blood endotoxin concentration and prognosis in dogs with pyometra. J Vet Med Sci 1998; 60: 1265-1267.

27. Pretzer SD. Clinical presentation of canine pyometra and mucometra: a review. Theriogenology 2008; 70: 359-363.

28. Purvis D, Kirby R. Systemic inflammatory response syndrome: septic shock. Vet Clin North Am Small Anim Pract 1994; 24 : 1225-1247.

29. Rubio A, Boyen F, Tas O, Kitshoff A, Polis I, Van Goethem $\mathrm{B}$, de Rooster H. Bacterial colonization of the ovarian bursa in dogs with clinically suspected pyometra and in controls. Theriogenology 2014; 82: 966-971.

30. Silva E, Leitao S, Ferreira-Dias G, Lopes da Costa L, Mateus L. Prostaglandin synthesis genes are differentially transcripted in normal and pyometra endometria of bitches. Reprod 
Domest Anim (Suppl 2) 2009; 44: 200-203.

31. Smith FO. Canine pyometra. Theriogenology 2006; 66: 610612.

32. Stone EA, Littman MP, Robertson JL, Bovee KC. Renal dysfunction in dogs with pyometra. J Am Vet Med Assoc
1988; 193: 457-464.

33. Whitehead ML. Risk of pyometra in bitches treated for mismating with low doses of oestradiol benzoate. Vet Rec 2008; 162: 746-749. 